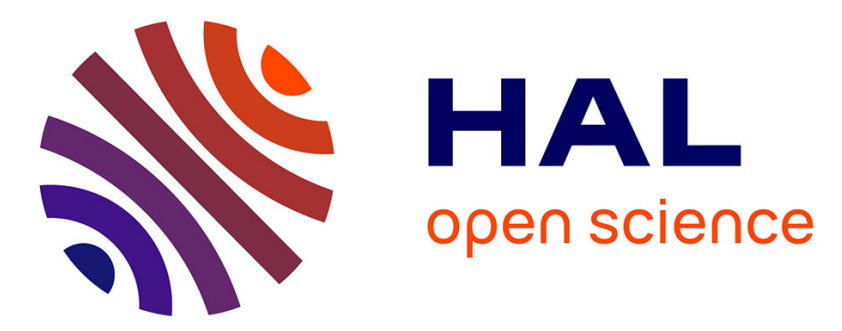

\title{
An Assessment Framework for Engineering Education Systems
}

Siegfried Rouvrais, Claire Lassudrie

\section{To cite this version:}

Siegfried Rouvrais, Claire Lassudrie. An Assessment Framework for Engineering Education Systems. SPICE 2014: 14th international Conference on Software Process Improvement and Capability dEtermination, Nov 2014, Vilnius, Lithuania. pp.250 - 255, 10.1007/978-3-319-13036-1_22 . hal-01175470

\section{HAL Id: hal-01175470 \\ https://hal.science/hal-01175470}

Submitted on 27 May 2021

HAL is a multi-disciplinary open access archive for the deposit and dissemination of scientific research documents, whether they are published or not. The documents may come from teaching and research institutions in France or abroad, or from public or private research centers.
L'archive ouverte pluridisciplinaire HAL, est destinée au dépôt et à la diffusion de documents scientifiques de niveau recherche, publiés ou non, émanant des établissements d'enseignement et de recherche français ou étrangers, des laboratoires publics ou privés. 


\title{
An Assessment Framework for Engineering Education Systems
}

\author{
Siegfried Rouvrais ${ }^{1,2}$ and Claire Lassudrie ${ }^{1}$ \\ ${ }^{1}$ Telecom Bretagne, Institut Mines Télécom, France \\ ${ }^{2}$ IRISA, CNRS UMR 6074 \\ $\{$ Siegfried.Rouvrais, Claire.Lassudrie\}@ $\}$ telecom-bretagne.eu
}

\begin{abstract}
Based on a return on experience, this paper describes and analyzes the application of model-based assessment taking inspiration from ISO 15504 Process Assessment Models and Measurement Framework to the domain of higher educational systems. The context of the analysis is a medium higher educational institution in engineering. A worldwide used educational framework for engineering education quality is first described. By analyzing its underlying assessment model and measurement framework, the authors propose some improvements inspired by ISO 15504 series.
\end{abstract}

Keywords: Assessment model, educational systems, engineering education, CDIO, SPICE.

\section{Introduction}

It is essential for higher educational institutions (HEI) to strengthen and better align their educational programs with new requirements by improving their quality. In higher education, several frameworks are defined for quality assurance, including accreditation systems (e.g. ABET in the USA or EUR-ACE in Europe for engineering education, EQUIS or AACSB for business schools). Lacking shared examples of evidence or best practices among HEIs, with inflexible reference models for accountability, these frameworks are not so well suited to continuous quality enhancement. On a day to day basis, managing the quality enhancement of an HEI still often remains informal. For HEIs, flexible and innovative models and processes are welcomed to support quality enhancement on a more continuous basis, as a complement to accreditations.

It is now recognized that software quality is largely dependent on the quality of the design, development and maintenance processes. Computer Science and Software Engineering methods can contribute to educational program lifecycle. As an example, the field of software engineering has experienced a crisis several years ago: too often software products were far from quality criteria. How can the assessment of quality in industry, e.g. software industry, inspire the assessment of quality in higher education in a flexible manner? Program designers might map Capability Maturity Models to pedagogical development $[1,2]$. 
In the context of HEI in engineering, the CDIO framework [3] is often used as a continuous complement to meet accreditation expectations. More than $100 \mathrm{HEI}$ worldwide are members of the CDIO initiative in 2014, from which many of them applied program self-assessment process [4]. This experience paper reports the application of such frameworks including maturity models specialized to HEIs in engineering [5, 6]. However, these frameworks have some limitations concerning assessment reliability, repeatability and accuracy. By making an analogy between the different elements of CDIO and the generic SPICE assessment models and measurement framework, the broad lines of a new assessment model and measurement framework based on CDIO standards can thus be proposed.

\section{The CDIO Framework for Quality Enhancement}

The international CDIO initiative [3] defines its vision as providing students with an education that stresses engineering fundamentals set, in a context of Conceive, Design, Implement and Operate real-world systems, processes and products. It identifies three overall goals:

- Master a deeper working knowledge of technical fundamentals,

- Lead in the creation and operation of new products, processes and systems,

- Understand the importance and strategic impact of research and technological development on society.

To meet those goals, the initiative has created a set of resources that support the achievement of proper curricula. In order to help different key stakeholders of engineering education to assess and improve the quality of undergraduate engineering education, the initiative defines a reference model of best practices that includes twelve Standards:

- Program Philosophy (Standard 1)

- Curriculum Development (Standards 2, 3 and 4)

- Design-implement Experiences and Workspaces (Standards 5 and 6)

- Teaching and Learning Methods (Standards 7 and 8), Learning assessment (Standard 11)

- Faculty Competence (Standards 9 and 10)

- Program Assessment (Standard 12)

Each Standard is defined by a description, a rationale, and a rubric, which is a six-point rating scale for assessing levels of compliance with a Standard. CDIO Standards, with the associated rubrics can be considered as an Assessment Model in the context of Engineering Education systems assessment and improvement. To help performing an assessment, some samples of evidence are provided with each level of each Standard. As a measurement framework, the levels seek to indicate progress towards the planning, the implementation and the adoption of each standard based on the evidences gathered. Compared to maturity scales defined for example in CMMi or ISO 15504-2, this is a very progressive approach, since full implementation of the standards is only considered from level 4.

0 . There is no documented plan or activity related to the standard; 
1. There is an awareness of need to adopt the standard and a process is in place to address it;

2. There is a plan in place to address the standard;

3. Implementation of the plan to address the standard is underway across the program components and constituents;

4. There is documented evidence of the full implementation and impact of the standard across program components and constituents;

5. Evidence related to the standard is regularly reviewed and used to make improvements.

Each standard is assessed individually; the final result is a radar profile of the Educational system. The CDIO Assessment Process is defined in Standard 12: "A CDIO program should be evaluated relative to the twelve CDIO Standards. Evidence of overall program value can be collected with course evaluations, instructor reflections, entry and exit interviews, reports of external reviewers, and follow-up studies with graduates and employers [...]. This feedback forms the basis of decisions about the program and its plans for continuous improvement."

\section{Improving the CDIO assessment model thanks to experiences}

CDIO approach was implemented since 2008 at Telecom Bretagne, a French graduate engineering school. Several CDIO self-assessments were carried out [5], by deans, teachers, and a group of students. The rating results are, however, to be taken with care. As non normative, the CDIO assessment model is sometimes informal and subject to confusion, but it is also strength in terms of usability. During these assessments, several weaknesses of the CDIO model were identified:

- poor repeatability: different assessors produced often different scoring due to lack of guidance (samples of evidence are not sufficient and have more an anecdotic character). Ratings of engineering education program quality may differ depending on assessors (eg being expert, alumni and program director) [7]. HEI program assessments are to be repeatable, as stated in SPICE-ISO 15504-2 standard for process assessment;

- difficulty to produce a scoring because of the duality of some rubrics (for example, level 1 involves both awareness and process implementation);

- lack of accuracy in the scoring: one cannot express that a level is only partially satisfied (e.g. satisfied only in some departments of the institution). As an example, CDIO Standard 1 contains the criteria "CDIO is adopted as the context for the engineering program [...]" at a given compliance level. But, assessor is left with the question of what would be "adopted as the context" (e.g. adopted by Management and/or program leaders, or even fully understood and adopted by the whole educational system and staff).

These experiences led us to propose an improved CDIO assessment model inspired from ISO 15504 assessment model requirements.

- First, the definition of the measurement scale should be improved by introducing the concept of Standard Attribute (SA). Each Standard Attribute defines a particular aspect of Standard compliance. For example, level 1 of 
the Generic Rubric, "Awareness about the Standard" corresponds to two Standard Attributes:

- SA 1.1: The stakeholders concerned by the Standard are aware of the importance of its adoption;

- SA 2.1: A process is in place to address the Standard and implement it.

- Second improvement concerns the introduction of the N-P-L-F attribute rating scale defined in ISO 15504-2, 2003, to measure the extent of achievement of each Standard Attribute. This allows a more accurate scoring of each Standard.

- Finally, the introduction of indicators associated to each Standard Attribute categorized as practices, work products (e.g., curriculum, course supports, questionnaires, interview reports) and resources (e.g., pedagogical resources, rooms, human resources) will permit to build a complete CDIO assessment framework and allow repeatable assessments and benchmarking between different institutions.

\section{Conclusion and Perspectives}

CDIO framework provides useful guidance for continuous improvement of an educational system on aspects such as strategy, curriculum development, pedagogical activities, learning experiences and workspaces. In this experience report, we have analyzed the limits and weaknesses of CDIO framework, considered as an educational assessment model. It does not provide a complete quality management model, as it does not address aspects such as learners support, relationships between research and education, or human resource management. Some frameworks based on Capability Maturity models have overcome these limitations to provide a complete model based on Enterprise SPICE [8, 9] or CMMI [2], and taking into account specific processes for educational systems. Some improvements inspired by ISO 15504 are thus proposed in this short paper to improve repeatability and accuracy of assessments.

Future works will involve the development of a complete process reference model and assessment model specific to Engineering Education by establishing a correspondence between CDIO standards and related process and practices issued from generic process reference models like SPICE Entreprise or more specific models dedicated to education. Following an approach similar to Team SPICE [10], processes related to the implementation of each standard may be identified. For example, Standard 1, "Adoption of CDIO as the context of Engineering Education", is linked to Enterprise Governance and Needs in SPICE Enterprise Reference Model. In addition, and in line with the new series of standards ISO 330xx, different quality characteristics in educational systems process assessment, such as flexibility, evolution, reliability, or scalability may be investigated. These new characteristics may be important in educational systems that need to adapt to fast technological or societal evolutions. 
Acknowledgments. The authors express their gratitude towards Ing. Samia EchChantoufi and Soukaina Bakrim, both senior engineering students at Telecom Bretagne in 2014. In the perspective of the 2015 educational program renewal at their institution, they analyzed models and processes for quality enhancement during a joint semester project, proposed to enhance the in place assessment models and processes, and implemented a software prototype to support multi-role assessment.

\section{References}

1. Lister, R.: What If We Approached Teaching Like Software Engineering? ACM InRoads, Computing Education Research, Vol 2(1) (2011)

2. M. M. Larrondo Petrie, M.M.: Towards an Engineering Education Capability Maturity Model. In Proceedings of the American Society for Engineering Education Annual Conference \& Expositions (2004)

3. Crawley, E., Malmqvist, J., Ostlund, S., and. Brodeur, D.: Rethinking Engineering Education: The CDIO Approach. Springer Verlag, 286 pages (2007)

4. Kontio, J., Granholm, P., Valmu, H., Mäntykoski, J., Kruusamäe, K., Aukstuoliene, M., Savulionienes, L., Munkebo Hussmann, P., and Edström, K.: Supporting Programme Development with Self- and Cross-evaluations - Results from an International Quality Assurance Project. Intl. Conference on Engineering Education, pp.816-823 (2012)

5. Lassudrie, C., Kontio, J., and Rouvrais, S.: Managing the Continuous Improvement Loop of Educational Systems: Students as key actors in program evaluation. In Proc. of the 9th intl. CDIO Conference. MIT \& Harvard School of Engineering and Applied Sciences (2013)

6. Rouvrais, S., Le Locat, C., and Flament, S.: Return on Experience from Sustainability Audits in European Engineering Educational Institutions. In Proceedings of the 41th intl. SEFI Conference: "Engineering Education Fast Forward". KU Leuven, Belgium (2013)

7. Malmqvist, J., Peterson L., and Arehag, M.: Ratings of Engineering Education Program Quality - Correlation between expert, alumni and program director assessments? In electronic Proc. of the $10^{\text {th }}$ Intl. CDIO conference, Universitat Politècnica de Catalunya, Barcelona, Spain (2014)

8. Enterprise SPICE Project team: Enterprise SPICE: An integrated Model for Enterprise-wide Assessment and Improvement. Technical Report, issue 1 (2010) http://ww.enterprisespice.com.

9. Mitasiunas, A. and Novickis, L.: Enterprise SPICE Based Education Capability Maturity Model. In:BIT 2011 Workshops, LNBIP 106, L. Niedrite, R. Strazdina, B. Wangler (Eds), pp. 102-116 (2012)

10. Amengual, E. and Mas, A.: Teamwork Best Practices in ISO/IEC 15504., In Proc. of the 9th Intl. Conference on Software Process Improvement and Capability Determination, pp. 106-112 (2009) 